Available online on 15.09.2020 at http://jddtonline.info
Open Access to Pharmaceutical and Medical Research
unrestricted non-commercial use, provided the original work is properly cited

Open $\odot$ Access

Research Article

\title{
Evaluation of Antioxidant activities and total phenolic content of hydro- ethanol extract from Phlomis bovei De Noé areal parts
}

\author{
Hind Amira*, Islam Amira, Fatima Benchikh, Hassiba Benabdallah, Walid Mamache, Smain_Amira \\ Laboratory of Phytotherapy Applied to Chronic Diseases, Department of Animal Biology and Physiology, Faculty of Nature and Life Sciences, \\ University of Setif 1,19000 , Algeria
}

\begin{abstract}
The plants of the genus Phlomis are native to Turkey, North Africa, Europe and Asia. Phlomis bovei De Noé (Lamiaceae) is a rare Algerian endemic plant, commonly known as Kayat El Adjarah. The objective of this study is to quantify the polyphenol content and to evaluate the antioxidant activities of the ethanolic extract (EthE) of Phlomis bovei De Noé. The plant extract was prepared by macerating 100 g of ground material in $1000 \mathrm{ml}$ of $85 \%$ ethanol for $72 \mathrm{~h}$, then the filtrate was evaporated using a rotary evaporator at a temperature of $45 \mathrm{C}$ and the filtrate was dried. The total content in polyphenols was determined using Folin Ciocalteu method. Flavonoid content in extracts was determined using Aluminum trichloride assay and the total content of tannins was determined according to Bate Smith method. The antioxidant activity was investigated in vitro by the DPPH (2, 2-diphenyl-1-picryl-hydrazyl), ABTS and iron chelating assays. The results indicate that the ethanol extract was rich in polyphenols and has an important capacity of scavenging the DPPH and ABTS free radical with an IC 50 of 0.05 and 0.018 mg/ml, respectively. However, in the ferrous ions chelating ability test, PBEE extract showed moderate chelating activity (IC $50=1.59 \pm 0.05 \mathrm{mg} / \mathrm{ml}$ ). To conclude, the obtained results may contribute to add possible scientific data to use Phlomis bovei industrially as herbal medicine and as supplementary sources for natural antioxidant drugs in food.
\end{abstract}

Keywords: antioxidant activity, ethanol extract, Phlomis bovei De Noé, polyphenol content.

Article Info: Received 12 August 2020; Review Completed 16 August 2020; Accepted 21 August 2020; Available online 15 September 2020

Cite this article as:

Amira H, Amira I, Benchikh F, Benabdallah H, Mamache W, Amira S, Evaluation of Antioxidant activities and total phenolic content of hydro-ethanol extract from Phlomis bovei De Noé areal parts, Journal of Drug Delivery and Therapeutics. 2020; 10(5):45-48 http://dx.doi.org/10.22270/jddt.v10i5.4339

*Address for Correspondence:

Hind Amira, Laboratory of Phytotherapy Applied to Chronic Diseases, Department of Animal Biology and Physiology, Faculty of Nature and Life Sciences, University of Setif 1, 19000, Algeria

\section{INTRODUCTION}

Free radicals contribute to more than one hundred disorders in humans including atherosclerosis, arthritis, ischemia and reperfusion injury of many tissues, central nervous system injury, gastritis, cancer and AIDS $^{1}$. Free radicals due to environmental pollutants, radiation, chemicals, toxins, deep fried and spicy foods as well as physical stress, cause depletion of immune system antioxidants, change in gene expression and induce abnormal proteins. The oxidation process is one of the most important routs for producing free radicals in food, drugs, and even living systems 1,2 .

The preservative effect of many plant spices and herbs suggests the presence of antioxidative constituents in their tissues ${ }^{3}$. Recently, interest has increased considerably in finding naturally occurring antioxidants for use in foods or medicinal materials to replace synthetic antioxidants, which are being restricted due to their carcinogenicity 4. Many medicinal plants contain large amounts of antioxidants such as polyphenols, which can play an important role in neutralizing free radicals.

The choice of our investigated plant is based on Phlomis bovei De Noé, a rare Algerian endemic plant, It is one among the nine endemic plants recorded in the Rapport National sur la Diversité Biologique ${ }^{5}$. This species belongs to the family Lamiaceae, which includes several species with proved medicinal properties. The purpose of this study was to evaluate the total phenolic content and the in vitro antioxidant activity to find out new potential sources of natural antioxidants.

\section{MATERIALS AND METHODS}

\subsection{Chemicals}

All chemicals were of analytical grade and purchased from sigma (St Louis, MO, USA) or Fluka Chemical Co. (Buchs, Switzerland). 


\subsection{Plant material}

The fresh areal parts of the plant P. bovei were harvested in June, 2018 from the region of Beni Aziz, wilaya of Setif. The identification was made by $\operatorname{Pr}$ Laouer Hocine (Faculty of Natural and Life Sciences, University of Sétif 1). The aerial part of the collected plant was cleaned, dried at room temperature and in the shade for 2-3 weeks

\subsection{Preparation of hydro-ethanol extract}

The hydro-ethanol extract of $P$. bovei was prepared from 50 $\mathrm{g}$ of ground material of the plant macerated in $500 \mathrm{ml}$ of ethanol (85\%) at room temperature and protected from light for 72 hours, with maximum agitation. The mixture is then filtered and evaporated to dryness using a rotary evaporator (BÜCHI) at a temperature of $40-50{ }^{\circ} \mathrm{C}$. Then this mixture is washed (defatted) several times with hexane and then evaporated to obtain the crude extract (EthE).

\subsection{Calculation of the plant extraction yield}

The yield of the plant extraction is the ratio between the weight of the extract and the weight of the plant to be treated. After extracting the active ingredients from the $P$. bovei plant, the yield is calculated using the following formula: $\mathrm{Y}=\mathrm{WE} / \mathrm{Wp} \times 100$ where:

$\mathrm{Y}=$ yield of the extract in percentage.

$\mathrm{WE}=$ weight of the extract in grams.

$\mathrm{Wp}=$ weight of the plant in grams.

\subsection{Determination of total phenolics, flavonoids and tannins contents}

\subsubsection{Determination of total phenolic content}

Total phenolic content was assessed by Folin Ciocalteu reagent as described by ${ }^{6}$. A volume of $100 \mu$ l of each extract was mixed with $500 \mu \mathrm{l}$ of Folin Ciocalteu reagent (diluted 10 times). After $4 \mathrm{~min}, 400 \mu \mathrm{l}$ of $7.5 \%$ of $\mathrm{Na}_{2} \mathrm{CO}_{3}$ solution was added. The final mixture was shaken and incubated in dark at room temperature for 1 hour and the absorbance of the reaction mixture was measured at $760 \mathrm{~nm}$. The amount of total polyphenols in different extracts was determined from a standard curve of gallic acid. The results were expressed as $\mathrm{mg}$ of gallic acid equivalent (GAE) per gram of dried plant extract.

\subsubsection{Determination of total flavonoid content}

Total flavonoid content was determined using aluminum chloride assay ${ }^{7}$. Briefly, $1 \mathrm{ml}$ of each tested extract or standard (quercetin) were mixed with $1 \mathrm{ml}$ of $\mathrm{AlCl}_{3}(2 \%)$. After $10 \mathrm{~min}$ of incubation, the absorbance against a prepared blank was measured at $430 \mathrm{~nm}$. The results were expressed as quercetin equivalent per gram of dry plant extract weight (mg QE/g DW) using a calibration curve of quercetin.

\subsubsection{Determination of total tannins content}

This was achieved by testing the capacity of the different extracts to precipitate haemoglobin from fresh bovine blood according to the method described by ${ }^{8}$. Briefly, a volume of each plant extract was mixed with an equal volume of hemolysed bovine blood (absorbance $=1.6$ ). After 20 minutes of incubation at room temperature, the mixture was centrifuged at $4000 \mathrm{rpm}$, and the absorbance of the supernatant was measured at $576 \mathrm{~nm}$ and the results were expressed as mg equivalent tannic acid per gram of extract dry weight (mg TAE/g DW) using a calibration curve of tannic acid.

\subsection{Evaluation of in vitro antioxidant activities}

\subsubsection{ABTS radical cation decolorization assay}

The radical scavenging assay against ABTS was measured using the method of 9 . The ABTS radical stock solution (7 $\mathrm{mM}$ in water) was mixed with $2.45 \mathrm{mM}$ potassium persulfate and kept for $12-16 \mathrm{~h}$ in the dark at room temperature. The solution was then diluted with methanol to give an absorbance of $\sim 0.7$ at $734 \mathrm{~nm}$. Then $50 \mu \mathrm{l}$ of sample was mixed with $1 \mathrm{ml}$ of ABTS mixture and kept for $30 \mathrm{~min}$ at room temperature in the dark. The absorbance of reaction mixture was measured at $734 \mathrm{~nm}$. Quercetin was used as positive control. All determinations were performed in replicates. Scavenging capability of test compounds was calculated from the following equation:

$\%$ inhibition $=$

$\frac{\text { Absorbance of control - Absorbance of test sample }}{\text { Absorbance of control }} \times 100$

To determine the $\mathrm{IC}_{50}$ values, a dose response curve was plotted. IC 50 is defined as the concentration sufficient to obtain $50 \%$ of a maximum scavenging capacity.

\subsubsection{DPPH scavenging activity}

The DPPH assay was based on the measurement of altering the purple colour to yellow of DPPH radical at $517 \mathrm{~nm}$ after reaction with antioxidant compound. The effect of antioxidants on DPPH radical was thought to be due to their hydrogen donating ability. DPPH'is a stable free radical and accepts an electron or hydrogen radical to become a stable diamagnetic molecule ${ }^{10}$. In this test, $50 \mu \mathrm{l}$ of different concentrations of the plant extract or standard was added to $1250 \mu \mathrm{l}$ of DPPH $(0.004 \%$ in methanol). All reagents were mixed and incubated for 30 minutes at room temperature and protected from light and then the absorbance was read at $517 \mathrm{~nm}$. Gallic acid was used as standard. The percentages of the DPPH free radical scavenging activity were calculated as follows:

$\%$ inhibition =

$$
\frac{\text { Absorbance of control - Absorbance of test sample }}{\text { Absorbance of control }} \times 100
$$

\subsubsection{Ferrous ion chelating activity}

The chelating effect of the extracts was determined according to the method of 11 . This assay is based on the inhibition of the formation of $\mathrm{Fe}^{+2}$-ferrozine complex after treatment of samples with $\mathrm{Fe}^{+2}$ ions. Briefly, $250 \mu \mathrm{l}$ of test material or EDTA at different concentration were added to $50 \mu \mathrm{l}$ of $\mathrm{FeCl}_{2}(0.6 \mathrm{mM}$ in distilled water) and $450 \mu \mathrm{l}$ of methanol. After $5 \mathrm{~min}$ of incubation, the reaction was initiated by the addition of $5 \mathrm{mM}$ ferrozine $(50 \mu \mathrm{l})$, the mixture was stirred and allowed to react at room temperature for $10 \mathrm{~min}$. The control contained all the reaction reagents except the extract and EDTA. The absorbance of the $\mathrm{Fe}^{2+}$-ferrozine complex was measured at $562 \mathrm{~nm}$. The chelating activity was expressed as a percentage using the following equation:

Chelating activity $(\%)=$

Absorbance of control - Absorbance of test sample Absorbance of control 
To determine the $\mathrm{IC}_{50}$ values, a dose response curve was plotted. $\mathrm{IC}_{50}$ is defined as the effective concentration of the test material that is required to chelate $50 \%$ of iron ions.

\subsection{Statistical analysis}

Results were expressed as means of triplicate \pm SD. Data were statistically analyzed with Graph Pad Prism ${ }^{\circledR}$ version 7.00 by the help of Student's t-test. Differences are considered significant when $\mathrm{P}<0.05$.

\section{RESULTS AND DISCUSSION}

\subsection{Yield extraction, total phenolics, flavonoids and tannins contents}

The extraction yield of EthE was 2.32\%. The plant extract was very rich in tannins (301.4 $\pm 0.0009 \mathrm{mg}$ TAE/g DW) and phenolics acid (164.20 $\pm 0.003 \mathrm{mg} \mathrm{GAE} / \mathrm{g} \mathrm{DW})$. Flavonoids content was found to be $18.34 \pm 0.0008 \mathrm{mg}$ QE/g DW.

Table 1: Yield extraction, total phenolics, flavonoids and tannins contents of Phlomis bovei EthE extract.

\begin{tabular}{|c|l|l|l|l|}
\hline Extract & \multicolumn{1}{|c|}{ Extraction yield \% } & $\begin{array}{c}\text { Total phenolics } \\
(\mathrm{mg} \mathrm{GAE} / \mathrm{g} \mathrm{Dw})\end{array}$ & $\begin{array}{c}\text { Total flavonoids } \\
(\mathrm{mg} \text { QE/g DW) }\end{array}$ & $\begin{array}{c}\text { Total tannins } \\
(\mathrm{mg} \text { TAE/g DW) }\end{array}$ \\
\hline EthE & 2.32 & $164.20 \pm 0.003$ & $18.34 \pm 0.0008$ & $301.4 \pm 0.0009$ \\
\hline
\end{tabular}

EthE: hydro-ethanol extract, GAE: gallic acid equivalent, QE: quercetin equivalent, TAE: tannic acid equivalent, DW: Dry weight. Results are expressed as means $\pm \mathrm{SD}(\mathrm{n}=3)$. DW: Dry weight.

\subsection{Antioxidant activity}

Antioxidant properties were investigated in EthE using free radical scavenging activity (against both DPPH and ABTS radicals) and metal chelating capacity. As Table 2 indicates, EthE showed a marked scavenging activity against radical ABTS $\left(\mathrm{IC}_{50}=0.018 \pm 0.0009 \mathrm{mg} / \mathrm{ml}\right)$. The plant extract also exhibited a good scavenging activity towards DPPH ( $\mathrm{IC}_{50}=$ $0.050 \pm 0.0018 \mathrm{mg} / \mathrm{ml})$. These activities remain lower than quercetin and gallic acid as positive standards $\left(\mathrm{IC}_{50}=0.002\right.$ \pm 0.002 and $0.002 \pm 0.00012 \mathrm{mg} / \mathrm{ml}$ ), respectively. It was observed that the iron chelating capacity of EthE was moderate $\left(\mathrm{IC}_{50}=1.59 \pm 0.058 \mathrm{mg} / \mathrm{ml}\right.$ ) compared to EDTA as reference drug $\left(\left(\mathrm{IC}_{50}=0.007 \pm 0.0007 \mathrm{mg} / \mathrm{ml}\right)\right.$.

Table 2: In vitro antioxidant activities of Phlomis bovei EthE and standards

\begin{tabular}{|l|l|l|l|}
\hline \multirow{2}{*}{ Extract } & \multicolumn{3}{|c|}{$\mathrm{IC}_{50}(\mathrm{mg} / \mathrm{ml})$} \\
\cline { 2 - 4 } & ABTS activity & DPPH activity & Chelating ability \\
\hline EthE & $0.018 \pm 0.0009^{* * * *}$ & $0.050 \pm 0.0018^{* * * *}$ & $1.59 \pm 0.058^{* * * *}$ \\
\hline GA & & $0.002 \pm 0.00012$ & \\
\hline Quer & $0.002 \pm 0.002$ & & $0.007 \pm 0.0007$ \\
\hline
\end{tabular}

EthE: Phlomis bovei hydro-ethanol extract; GA: gallic acid, Quer: quercetin, EDTA: ethylenediaminetetraacetic acid, DPPH: 2,2-diphenyl-1picrylhydrazyl, ABTS: 2, 2'-azinobis (3-ethylbenzothiazoline-6-sulfonic acid). ${ }^{* * *} \mathrm{p}<0.0001$ compared to correspondent standards.

\section{DISCUSSION}

The role of free radicals in many disease conditions has been well established. Several biochemical reactions generate reactive oxygen species in our body. These are able to damage crucial bio-molecules and they lead to disease conditions, if they are not effectively scavenged by cellular constituents 2 . The harmful action of free radicals can be inhibited by antioxidant substances, which scavenge the free radicals and detoxify the organism. Several studies pointed out that many plant extracts and different classes of phytochemicals have been shown to have antioxidant activity $12,13,14,15$. Antioxidants are compounds that can delay or inhibit the oxidation of lipids and other molecules and by doing so inhibit the initiation and propagation of oxidative chain reactions. They act by one or more of the following mechanisms: reducing activity, free radical scavenging, potential complexation of pro-oxidant metals and quenching of singlet oxygen ${ }^{16}$. Nowadays, the search for newer natural antioxidants, especially of plant origin, has been increasing. Plants have been a constant source of drugs and recently, much emphasis has been placed on finding new therapeutic agents from medicinal plants. Today many people prefer to use medicinal plants rather than chemical drugs ${ }^{17}$. Plant secondary metabolites such as polyphenols, play an important role in the defense against free radicals. Medicinal plant parts (roots, leaves, stems, flowers and fruits) are commonly rich in phenolic compounds, such as flavonoids, tannins, stilbenes, coumarins, lignans 18.

The antioxidant properties of polyphenols are due to their redox properties, which allow them to act as reducing agents, hydrogen donators, metal chelators and single oxygen quenchers. Polyphenolics exhibit a wide range of biological effects which may be attributed to their free radical scavenging and antioxidant activity 17,19 .

In the present study, after defating the hydro-ethanol extract with hexane, the extraction yield was $2.32 \%$. The extraction yield percent depends mainly on the extraction procedure (temperature, solvent ratio and the methods of extraction). Antioxidant activity of plant extracts cannot be evaluated by a single method. In a preliminary study, the antioxidant activity of the plant extract in study was evaluated using ABTS, DPPH and metal chelating activities.

The ABTS assay is based on the inhibition of the absorbance of the radical cation 2,2'-azino-bis (3-ethylbenzothiazoline6-sulfonate) $\left(\mathrm{ABTS}^{+}\right)$solution when it is exposed to an antioxidant 9 . The scavenging ability against ABTS radical indicates the power of the extract to act as electron donors or hydrogen donors in free radical reactions 20 . The scavenging of the $\mathrm{ABTS}^{+}$radical by the plant extract in the 
present study was found to be very strong compared to the DPPH and the ion chelating methods used in this study. This shows that $P$. bovei extract presents a good ability to scavenge the ABTS radical. It was reported that high molecular weight phenolic compounds such as tannins have more ability to scavenge free radicals such as ABTS • 21 .

The DPPH assay has become quite popular in natural antioxidant studies. One of the reasons is that this method is simple and highly sensitive. The DPPH radical is often used as an indicator to test the ability of the extract to give a hydrogen atom or an electron and therefore its anti-radical or antioxidant capacity ${ }^{22}$. The plant extract in study shows a powerful scavenging activity (IC $=0.050 \pm 0.0018 \mathrm{mg} / \mathrm{ml}$ ). Thus, antioxidant molecules can neutralize DPPH-free radicals; by providing hydrogen atoms or donating electrons and convert them to a colorless/bleached substance $(2,2$ diphenyl-1 hydrazine or equivalent hydrazine substituted), resulting in a decrease in absorption at the $517 \mathrm{~nm}$ level. The strong activity of the plant extract to scavenge the radical DPPH could be attributed to its richness in tannins (301.4 \pm $0.0009 \mathrm{mg}$ TAE$/ \mathrm{g} \mathrm{DW})$ and phenolics acids (164.20 \pm 0.003 mg GAE/g Dw). Thus, secondary metabolites present in the plant extract can neutralize DPPH-free radicals; by provide hydrogen atoms or donate electrons and convert them to a colorless/bleached substance (2,2-diphenyl-1 hydrazine or equivalent hydrazine substituted), resulting in a decrease in absorption at the $517 \mathrm{~nm}$ level ${ }^{23}$.

Metal ion chelating capacity plays a significant role in antioxidant mechanisms, since it reduces the concentration of the catalysing transition metal in lipid peroxidation ${ }^{20}$. The observed results shown in table 2, demonstrate that EthE extract inhibited interfered in the inhibition of the formation of ferrous and ferrozine complex, suggesting that the extract exhibited appreciable chelating ability.

\section{CONCLUSION}

The results of the present work indicate that the hydroethanol extract from Phlomis bovei is rich in polyphenols mainly tannins. It is also shown that the plant extract possess high radical scavenging and moderate metal chelating activities. These assays are useful for establishing the ability of phenolics to scavenge free radicals and chelate iron ions and have important applications for the pharmaceutical and food industries. However, further work to isolate individual phenolic compounds and study their in vivo antioxidant activities is warranted.

\section{CONFLICT OF INTEREST}

The authors declare that they have no conflicts of interest

\section{ACKNOWLEDGMENTS}

We thank the Algerian Ministry of Higher Education and Scientific Research (MESRS) for research support. Authors would like also to thank Prof. Hocine LAOUER (Laboratory of Valorization of Natural Biological Resources, University of Sétif1, Algeria) for the identification of the plant material.

\section{REFERENCES}

[1]. Kumpulainen JT, Salonen JT (1999). Natural Antioxidants and Anticarcinogens in Nutrition, Health, and Disease, The Royal Society of Chemistry, UK pp 178- 187.

[2]. Halliwell B, Gutteridge JMC, Cross CE. Free radicals, antioxidants and human disease: where are we now? J. Lab Clin Med, 1992; 119:598-620.
[3]. Hirasa K, Takemasa M. Spices and herbs: Basic concepts. In Spice Science and Technology New York, USA: Marcel Dekker, Inc. 1998, pp. 9-11.

[4]. Velioglu, Y. S., Mazza, G., Gao, L., \& Oomah, B. D. Antioxidant activity and total phenolics in selected fruits, vegetables, and grain products. Journal of Agricultural Food and Chemistry, 1998; 46:4113-4117

[5]. Quezel P, Santa S. Nouvelle flore de l'Algérie et des régions désertiques meridionales, C.N.R.S, Paris, 1962, p. 805.

[6]. Li HB, Cheng KW, Wong CC, Fan KW, Chen F, Jiang Y. Evaluation of antioxidant capacity and total phenolic content of different fractions of selected microalgae. Food Chem, 2007; 102:771776.

[7]. Bahorun T, Gressier B, Trotin F, Brunete C, Dine T, Vasseur J, Luyckx M, Cazin M, Pinkas M. Oxygen species scavenging activity of phenolic extract from Hawthorn fresh plant organs and pharmaceutical preparations. ArzneimForsch/Drug Res, 1996; 46:1086-1089.

[8]. Bate-Smith EC. Haemanalysis of tannins, the concept of relative astringency. Phytochemistry, 1973; 12:907-912.

[9]. Re R. Antioxidant activity applying an improved ABTS radical cation decolourization assay. Free Radical Bio Med, 1999; 26:1231-1237.

[10]. Shekhar TC and Anju G. Antioxidant Activity by DPPH Radical Scavenging Method of Ageratum conyzoides Linn. Leaves. American Journal of Ethnomedicine, 2014; 1(4):244-249.

[11]. Decker EA, Welch B. Role of ferritin as lipid oxidation catalyst in muscle food. J Agr Food Chem, 1990; 36:674-677

[12]. Cao GH, Sofic E, Prior RL.. Antioxidant capacity of tea and vegetables. J Agri Food Chem, 1996; 44:3426-3431.

[13]. Zheng W and Wang S. Antioxidant activity and phenolic composition in selected herbs. J Agr Food Chem, 2001; 49:51655170.

[14]. Dehpour AA, Ebrahimzadeh MA, Fazel NS, Mohammad NS. Antioxidant activity of the methanol extract of Ferula assafoetida and its essential oil composition. GRASAS Y ACEITES, 2009; 60(4):405-412, DOI: 10.3989/gya.010109.

[15]. Benchikh F, Amira S, Benabdallah H. The evaluation of antioxidant capacity of different fractions of Myrtus communisL.leaves. Annual Research \& Review in Biology, 2018; 22(5):1-14.

[16]. Mehlous S, Benchikh F, Benabdallah H, Loucif K, Kaoudoune C, Laouer H, Amira S. Evaluation of antioxidant activity and polyphenols content of the hydro-methanolic extract from Saccocalyx satureioides Coss and Dur. Journal of Drug Delivery and Therapeutics, 2020; 10(4):188-190

[17]. Piluzza G and Bullitta S. Correlations between phenolic content and antioxidant properties in twenty-four plant species of traditional ethnoveterinary use in the Mediterranean area, Pharmaceutical Biology, 2011; 49:3:240-247, DOI: 10.3109/13880209.2010.501083.

[18]. Cai YZ, Luo Q, Sun M Corke. Antioxidant activity and phenolic compounds of 112 Chinese medicinal plants associated with anticancer. Life Sci, 2004; 74:2157-2184

[19]. Soobrattee M, Neergheen VS, Luximon-Ramma A, Aruoma OI, Bahorum T. Phenolics as potential antioxidant therapeutic agents: Mechanism and actions. Mut Res, 2005; 579:200-213.

[20]. Prior RL, Wu X, Schaich K. Standardized Methods for the Determination of Antioxidant Capacity and Phenolics in Foods and Dietary Supplements. J Agr Food Chem, 2005; 53:42904302.

[21]. Hagerman AE, Riedl KM, Jones GA, Sovik KN, Ritchard NT, Hartzfeld PW, Riechel TL. High molecular weight plant polyphenolics (tannins) as biological antioxidants. J Agr Food Chem, 1998; 46:1887-1892.

[22]. Kaoudoune C, Benchikh F, Benabdallah H, Loucif K, Mehlous S, Amira S. Gastroprotective effect and in vitro antioxidant activities of the aqueous extract from Artemisia absinthium L. aerial parts. Journal of drug delivery and therapeutics, 2020; $10(4): 153-156$.

[23]. Loucif K, Benabdallah H, Benchikh F, Mehlous S, Ben Souici C, Amira S. Total Phenolic Contents, DPPH Radical Scavenging and $\beta$-Carotene Bleaching Activities of Aqueous Extract from Ammoides atlantica. Journal of Drug Delivery and Therapeutics. 2020; 10(3-s):196-198. 